Article

\title{
Study of design and research of new welding manipulators on the example of an L-type positioner
}

\author{
Paweł Cegielskii ${ }^{1, *}$, Dariusz Golańskii ${ }^{1}$, Paweł Kołodziejczak ${ }^{1}$, Andrzej Kolasa ${ }^{1}$, Tadeusz Sarnowski ${ }^{2}$, \\ Bogusław Silbert ${ }^{2}$, Yevhen Krykavskyy ${ }^{3}$ \\ ${ }^{1}$ Warsaw University of Technology, Poland \\ Prof. Dariusz Golański, d.golanski@wip.pw.edu.pl; \\ Paweł Kołodziejczak, Ph.D. Eng., p.kolodziejczak@wip.pw.edu.pl; \\ Prof. Andrzej Kolasa, akolasa@wip.pw.edu.pl; \\ 2 ZAP Robotics in Ostrów Wielkopolski, Poland \\ Tadeusz Sarnowski, Ph.D. Eng., sarnowski@zap-robotyka.com.pl; \\ Bogusław Silbert, M.Sc., b.silbert@zap-robotyka.com.pl; \\ ${ }^{3}$ Lviv Polytechnic National University, Ukraine \\ Prof. Yevhen Krykavskyy; ywkryk@polynet.lviv.ua; \\ * Correspondence: Paweł Cegielski, Ph.D. Eng., pcegiels@wip.pw.edu.pl
}

Received: 08.05.2019; Accepted: 29.07.2019

\begin{abstract}
The development, testing and implementation of a new construction of a multi-axis L-type welding positioner designed to work with an industrial robot, distinguished by a wide range of movements, high load capacity and working space is a difficult task. Due to the special, unique nature of this type of devices, their research is not the subject of dedicated standards and detailed descriptions of literature and, are based primarily on their own manufacturers' procedures. The article traces the creative process in the development and implementation of the "L" positioner as part of the research and development of new types of machines at PPU "ZAP Robotics" in Ostrów Wielkopolski in cooperation with the Department of Welding Engineering at the Warsaw University of Technology.
\end{abstract}

Keywords: positioner; manipulator; external robot axis; FEM; off-line programming

\section{Introduction}

In the case of robotization of many technological processes, including arc welding, thermal cutting, coating and assembly, there may be a need for complex, multi-axis manipulation of workpieces with respect to the robot. For this purpose, positioners are commonly used - handling machines (positioning and/or working movements, even simultaneously with the movements of the robot), objects attached to the working table, usually through special equipment. They enable machining in the most convenient positions and/or allow access to these places $[1,2,6 \div 8,16]$.

The most versatile are two-axis positioners with a rotary work table ( $\mathrm{O}$ axis in Fig. 1 ) and the possibility of one-way tilting ( $\mathrm{P}$ axis in Fig. 1). The rotation of the table significantly facilitates reaching the robot to places that are out of its reach, and its tilt additionally supports obtaining the best technological machining position, e.g. welding position. This type of manipulation is usually achieved by tilting the rotary table inside a compact, often very rigid body in the range usually not exceeding $+/-90 \div 100^{\circ}$ (Fig. 1a). Fastening the table on the extended arm extends the range of its inclination up to $+/-180^{\circ}$, but often at the price of less rigidity and load capacity (Fig. 1b). Against this background, constructions with a revolving table located at the end of the horizontal beam of the L-shaped swinging arm stand out the most (Fig. 1c).

"L" type positioners have special predispositions to manipulate spatial objects of considerable size. Their advantage over standard constructions is manifested, among others, in such features as [2,3]:

- fully usable, full range of tilt of the manipulated object by rotating the "L" arm by up to $360^{\circ}$ (in both directions), allowing it to be set even in completely rotated position;

- comfortable location of the manipulated object in relation to the robot's range - the object practically doesn't change height regardless of the tilt;

- natural balancing of the manipulated object by bringing the load center of gravity closer to the axis of rotation of the "L" arm (axis P in Fig. 1c) and the resulting reduction of generated torque; 
- the possibility of additional load balancing by means of a replaceable counterweight, mounted on the top of the swinging "L" arm (Fig. 1c);

- the possibility of additional balancing by raising or lowering the place of fixing of the horizontal beam of the "L" arm (Fig. 1c);

- in some constructions, especially those intended for less demanding mechanization, the "L" arm is also raised and lowered together with its axis of rotation;

- possibilities of building symmetrical versions - two-station (5-axis).

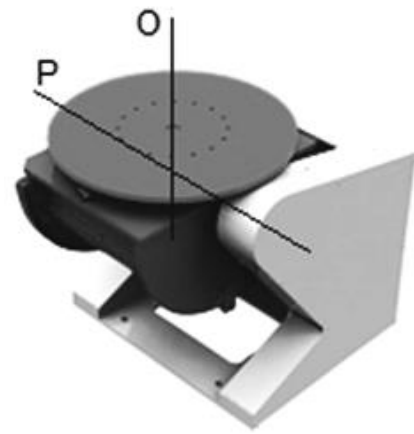

(a)

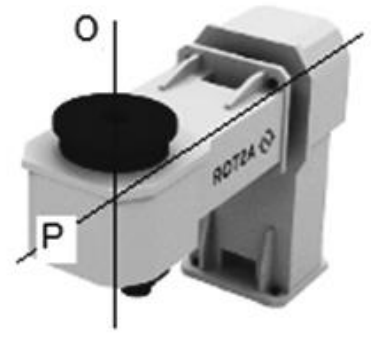

(b)

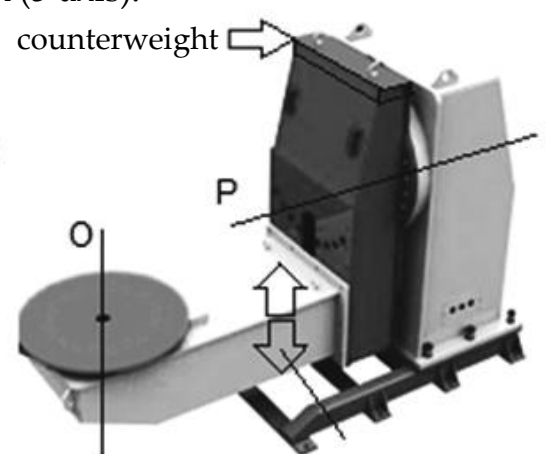

arm $\mathrm{L}$ beam adjustment directions

(c)

Fig. 1. Double-axis positioners: a) conventional, b) with rotating arm (ASTOR), c) type "L"

It should be added that full use of the "L" structure as the external axes of an industrial robot forces drives to be controlled continuously, i.e. close to the robot's own axes and based on the same application program. This, of course, applies to the discussed structure, which, due to the lack of drive unification in relation to various robot manufacturers, is a universal structure prepared for the installation of drive units adapted to various control systems.

The article examines a multi-stage, complex creative process in the development and implementation of a number of "L" positioners (Fig. 2) as part of the research and development of new machine types at PPU "ZAP Robotics" in Ostrów Wielkopolski in cooperation with the Welding Engineering Department of the Warsaw University of Technology. The whole project includes the development of "L" positioners, as well as other types of handling machines [2].

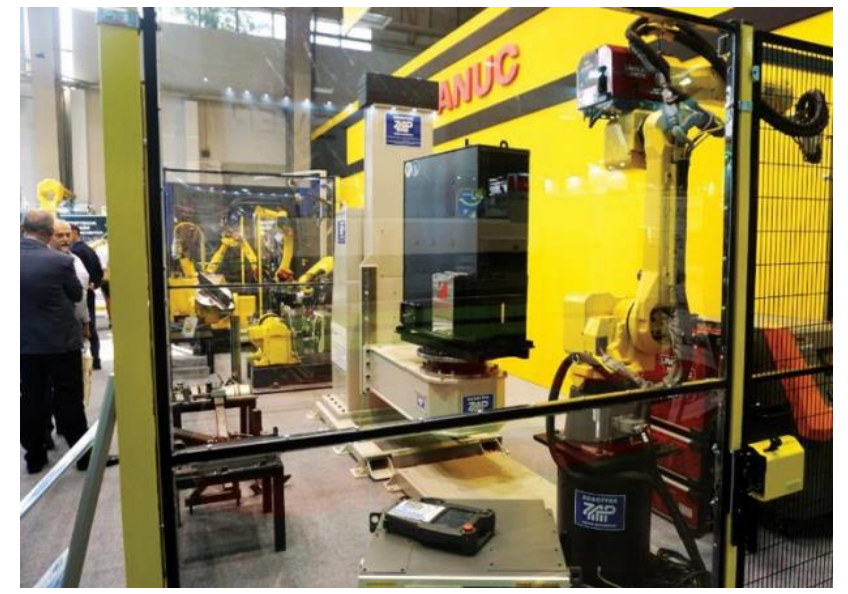

(a)

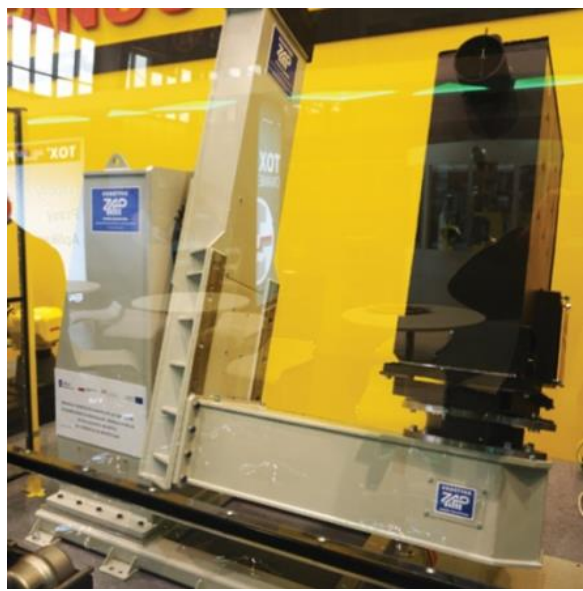

(b)

Fig. 2. Prototype of the L-type positioner with a $500 \mathrm{~kg}$ load capacity presented at the ITM 2019 fair

\section{Structural development of the positioner}

The main parameters adopted for the developed "L" positioners include [2]:

- two-axis basic positioner with a rotary arm in the shape of the letter "L", ended with a rotary working table (Fig. 3);

- two basic units with a load capacity of 250 and $500 \mathrm{~kg}$;

- two sizes of maximum space: 1.5 × $1.5 \times 1.5 \mathrm{~m}$ (for $250 \mathrm{~kg}$ load capacity) and $2.0 \times 2.0 \times 2.0 \mathrm{~m}$ (for $500 \mathrm{~kg}$ load capacity);

- positioning repeatability not worse than $\pm 0.1 \mathrm{~mm}$;

- maximum welding current not less than $500 \mathrm{~A}$; 
- universal design, prepared for installation of drive units adapted to various control systems (robot manufacturers);

- rotary axes of the working table and arm controlled in a continuous way, fully synchronized with the movements of the robot.

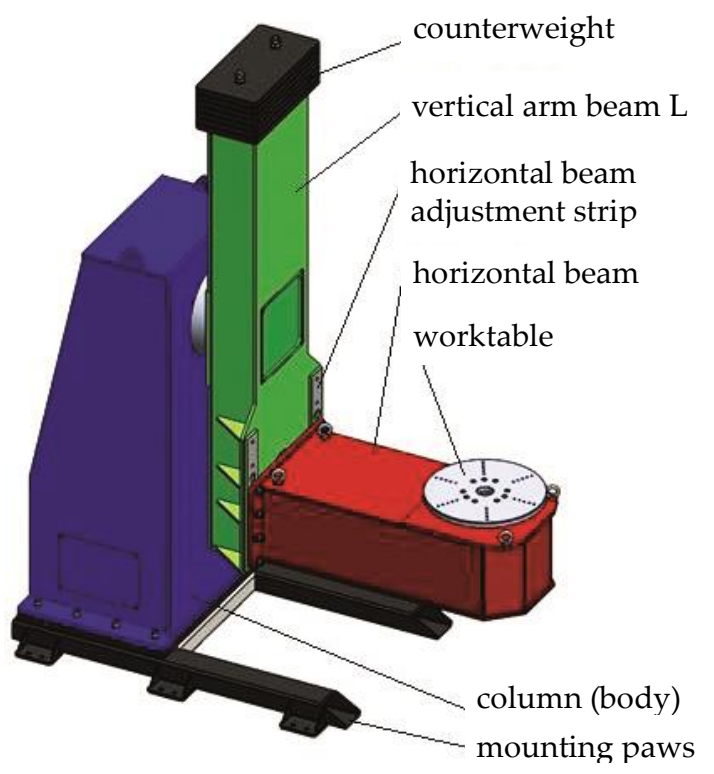

(a)

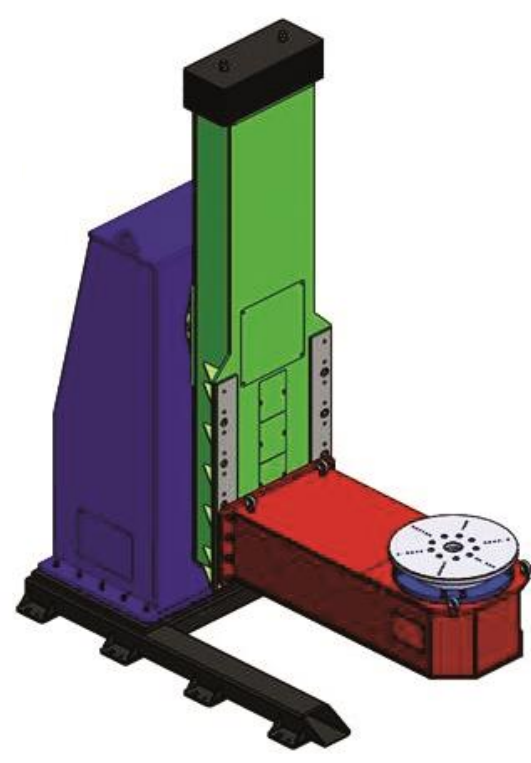

(b)

Fig. 3. 3D models of L-type positioner obtained during CAD structural modeling: a) original design, b) final project designed to build a prototype

Due to the size of the positioner, the problem of effective enforcement of free manipulation in the area of the assumed workspace appeared at the initial design stage in relation to the ergonomics of the operator's work in the loading and unloading phases. This issue was discussed in detail in earlier publications [2].

The final form of the positioner, including its key dimensions, sheet thicknesses and subassemblies (bearings, drives) were the result of a number of iterations of the structure in the processes of motion simulations of CAD models in the off-line programming environment [3] and of the FEM finite element calculations [4] (discussed in more detail in separate publications). Figure 3 compares the original design to the one obtained as a result of research and intended to build a prototype. The following are examples of structural changes introduced to the original design in subsequent project stages. First, the positioner base was modernized by extending the mounting lugs' profiles. This resulted in better stability and rigidity of the manipulator. As a result of the changes, the weight of the base also changed - from 170 to $257 \mathrm{~kg}$ (Fig. 4).
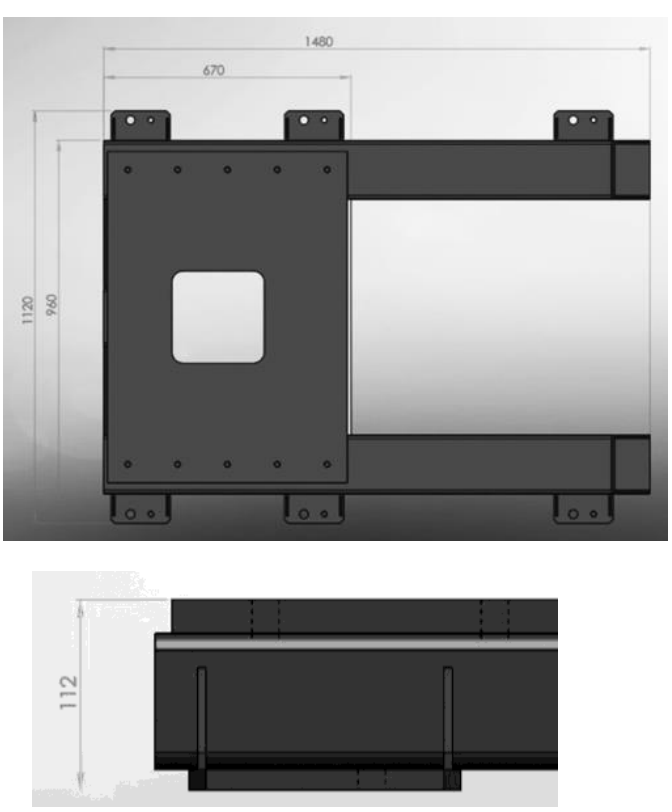

(a)

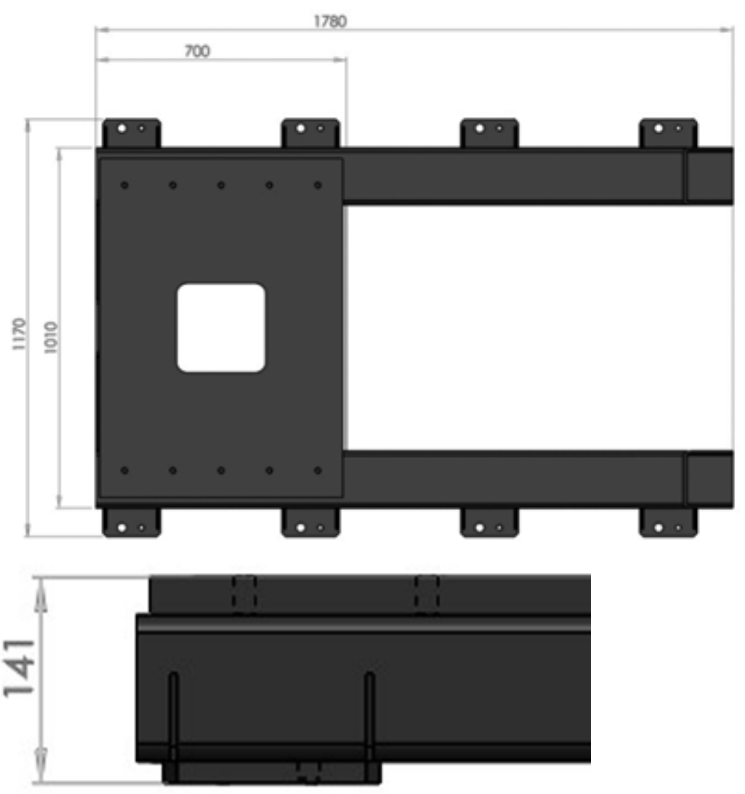

(b)

Fig. 4. Modernization of the "L" positioner base: a) before modernization, b) new, elongated and reinforced base version 
As part of the development of the "L" arm vertical beam, which is key from the point of view of the positioner's functionality and maximum deformations (deflections), a number of modifications were also introduced (Fig. 5).

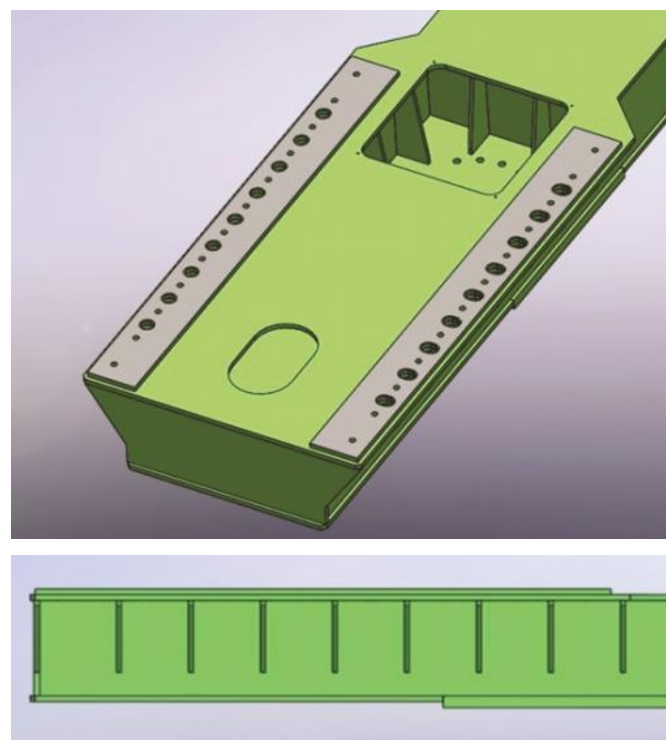

(a)
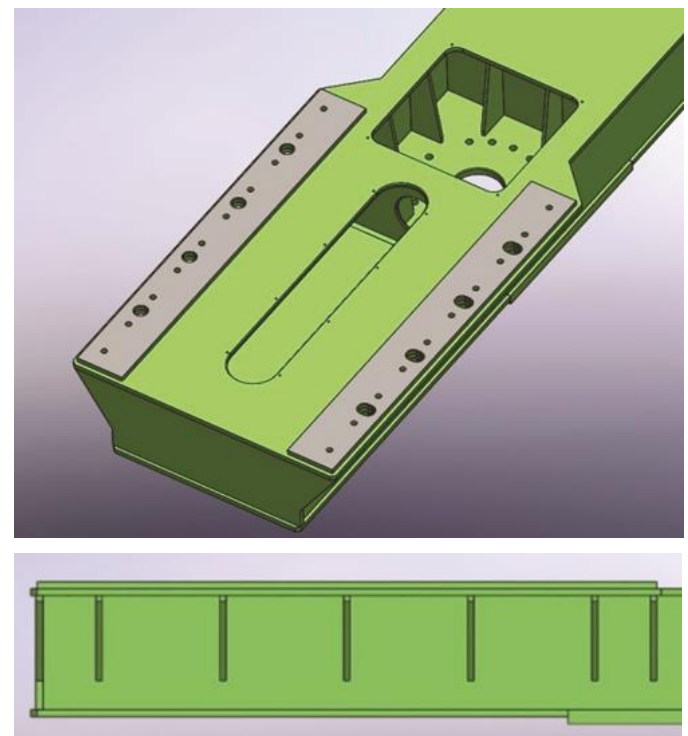

(b)

Fig. 5. Modernization of the vertical beam of the " $L$ " arm: a) before modernization, $b$ ) the new version

The transverse beam adjustment stroke has been increased from $100 \mathrm{~mm}$ to $200 \mathrm{~mm}$ and the number of adjustment positions has been reduced from an excess of 9 to 4 . The horizontal beam adjustment bar has been shortened from $1200 \mathrm{~mm}$ to $1000 \mathrm{~mm}$. The ribbing of the beam has changed (strengthened). The internal cutout has also been increased due to the need to route cables regardless of the horizontal beam mounting position.

An intermediate flange has been added to the horizontal beam to secure the hub of the working table's rotation axis. The changes were made mainly due to the expected, troublesome surface treatment from the inside of the beam and to strengthen it (Fig. 6).

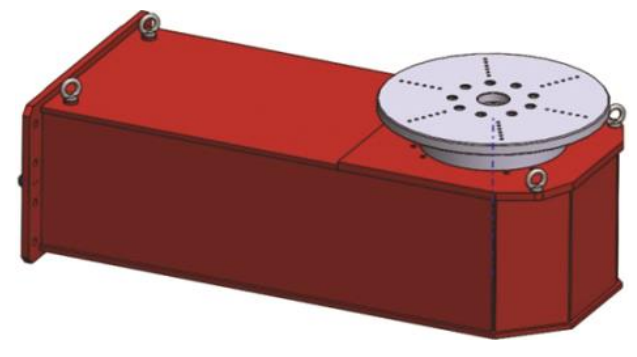

(a)

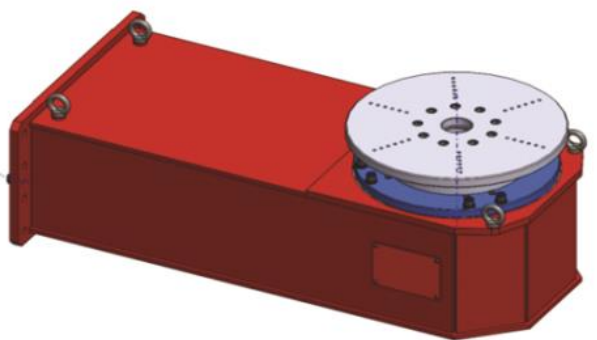

(b)

Fig. 6. Working table horizontal bar: a) before, b) after modernization and adding the intermediate flange

\section{Motion simulations in off-line mode}

Effective movement verification of positioners can be carried out by means of movement simulations in a virtual environment for programming robots in offline mode [10]. Own research using the Fanuc ROBGUIDE system concerned both the functional aspects of the designed structure and its interaction with robots and other manipulators [3]. In this case, the benefits of using off-line simulations instead of building and testing the physical model were undeniable:

- saving time;

- radical cost reduction;

- increasing the safety of people and other machines;

- the ability to detect geometric errors in the devices and mechanisms tested;

- the ability to detect errors in motion sequences;

- the ability to check, by simulation, the correctness of interaction with the robot within a hypothetical production nest. 
First, static geometric tests (without programmed motion) were carried out to check the cooperation of "L" positioners with the declared maximum space, simulated with manipulation objects filling it (Fig. 7). Then, the study was expanded to include the positioner's cooperation with typical industrial robots. To this end, the workspaces of the selected welding robots were combined (excluding the length of the tool mounted at the end of the robot) with the spaces of the tested positioner. The analysis had a visual character - 3D views and plan views of subsequent combinations were observed in search of the largest common area between both spaces, reflecting the robot's ability to operate against potential loading (Fig. 8).

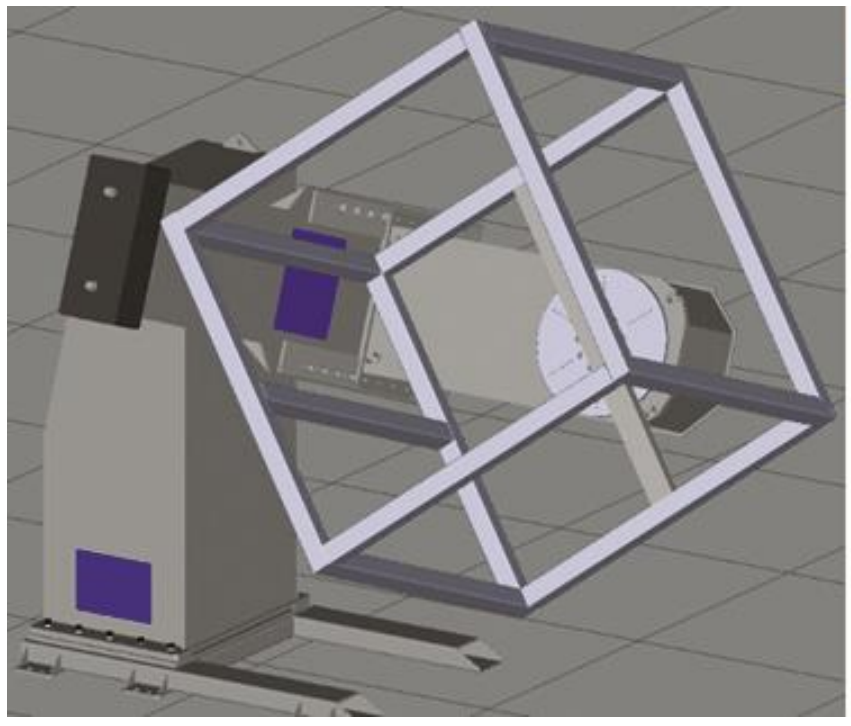

(a)

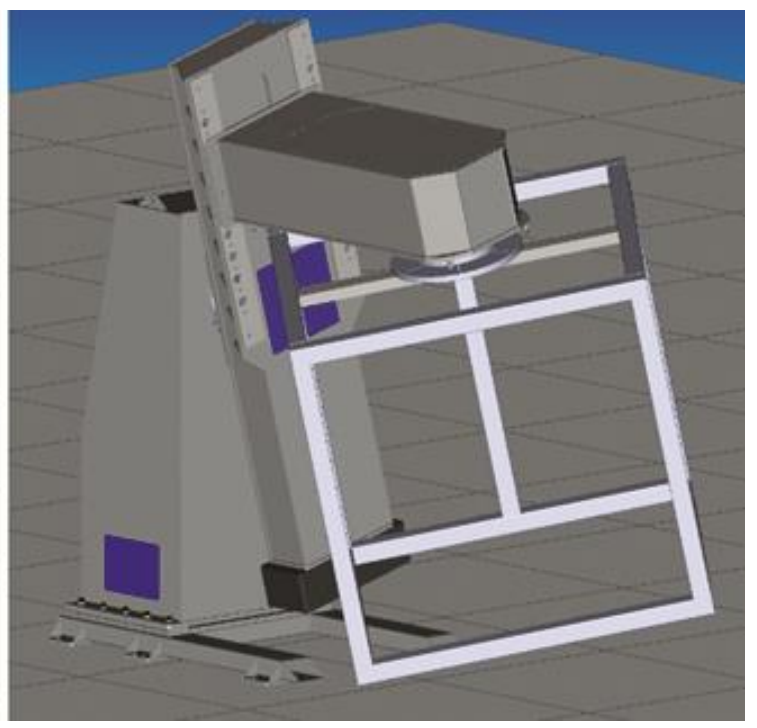

(b)

Fig. 7. Visualizations of interoperability of the tested CAD model of the L-type positioner with a capacity of $500 \mathrm{~kg}$ with the object filling the maximum space

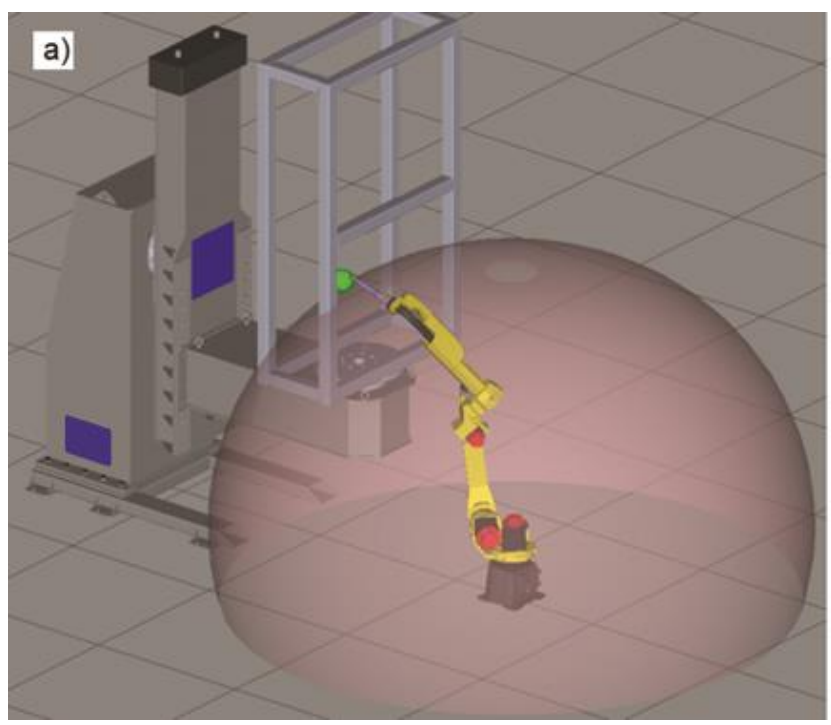

(a)

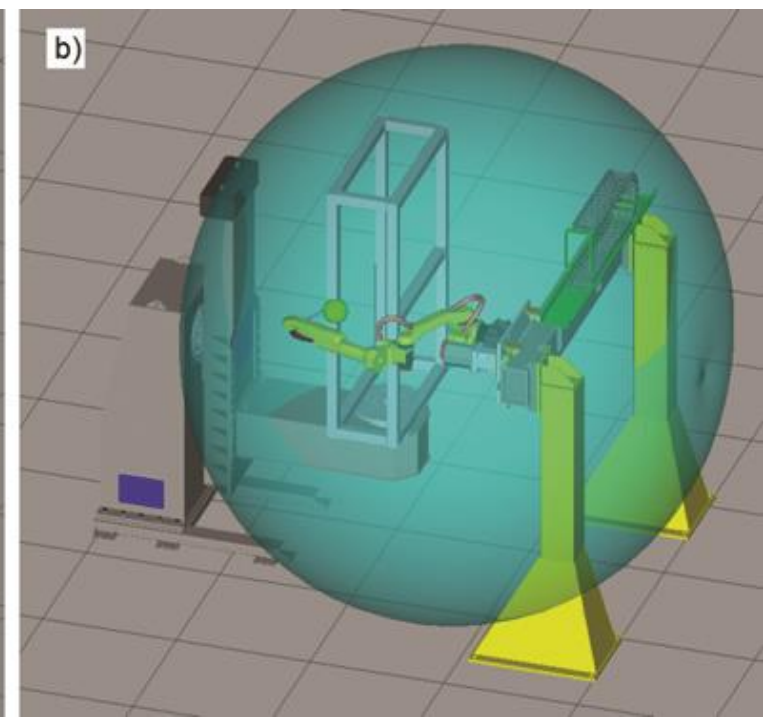

(b)

Fig. 8. Visualizations of cooperation of the tested CAD model of L-type positioner with a capacity of $500 \mathrm{~kg}$ with standard sized industrial robots (Fanuc 100iC): a) robot mounted to the ground, b) robot mounted in a wall position on the gate moving track

The high usability of both "L" positioner axes has been demonstrated, while at the same time clear limits of such a large space in cooperation with the range of standard welding robots. The maximum space of the "L" positioners in both sizes ( 250 and $500 \mathrm{~kg}$ ) is not fully reached with the robot arm of standard size (Fig. 8a). Only the use of the gate track (Fig. 8b) can be an important convenience. A much less troublesome floor track of the same length attached directly to the ground turned out to be insufficient. Detailed analyzes have shown that a slight increase in the floor track guarantees the best conditions for cooperation. This prompted the implementers to develop, as part of the project, a gantry track with standing, as for the floor, robot driving position. An interesting alternative to the railways turned out to be the use of a welding robot with an extended Fanuc 710iC arm, mounted on a slight elevation in a standing position. 
Spatial parameters related to the orientation and movement of the tool and the welding position are of great importance for the process, they are mutually dependent and as a consequence must be considered together (Figs. 3 and 4) [1,12:14]. Next, for the best configurations and settings resulting from static tests, more advanced activities were carried out - using the coordinated movement of the robot and the tested " $L$ " positioners. Their goal was to verify the effective service range (ability to cooperate). The verification criterion was the ability to achieve a specific - vertical orientation of the electrode axis of the electrode holder mounted at the end of the robot arm (Fig. 9).
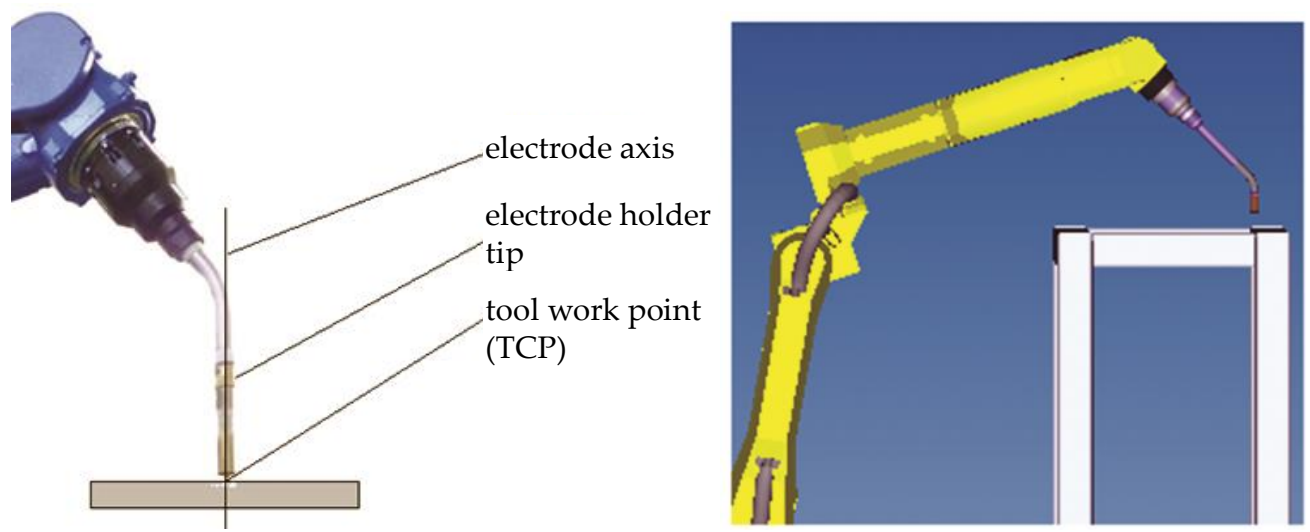

Fig. 9. Vertical orientation of the electrode axis of the MIG/MAG electrode holder mounted on the end of the robot's arm: real view and visualization in an off-line environment ROBGUIDE (Fanuc)

The research included both reaching the designated points in space with the tool and between them along a programmed, continuous path. The choice of vertical orientation was dictated by the difficulty in achieving it, especially at the limits of the robot's range, and at the same time it is the correct orientation of the electrode when welding in a flat position.

Collision hazards with positioner structural elements, errors in motion sequences, lack of coverage, orientation, etc. were analyzed. To this end, the motion sequences were programmed, and visual studies concerned the analysis of simulated reproduction of the robot's working motion without and in conjunction with the simultaneous manipulation movement of the tested positioner CAD model (Fig. 10).

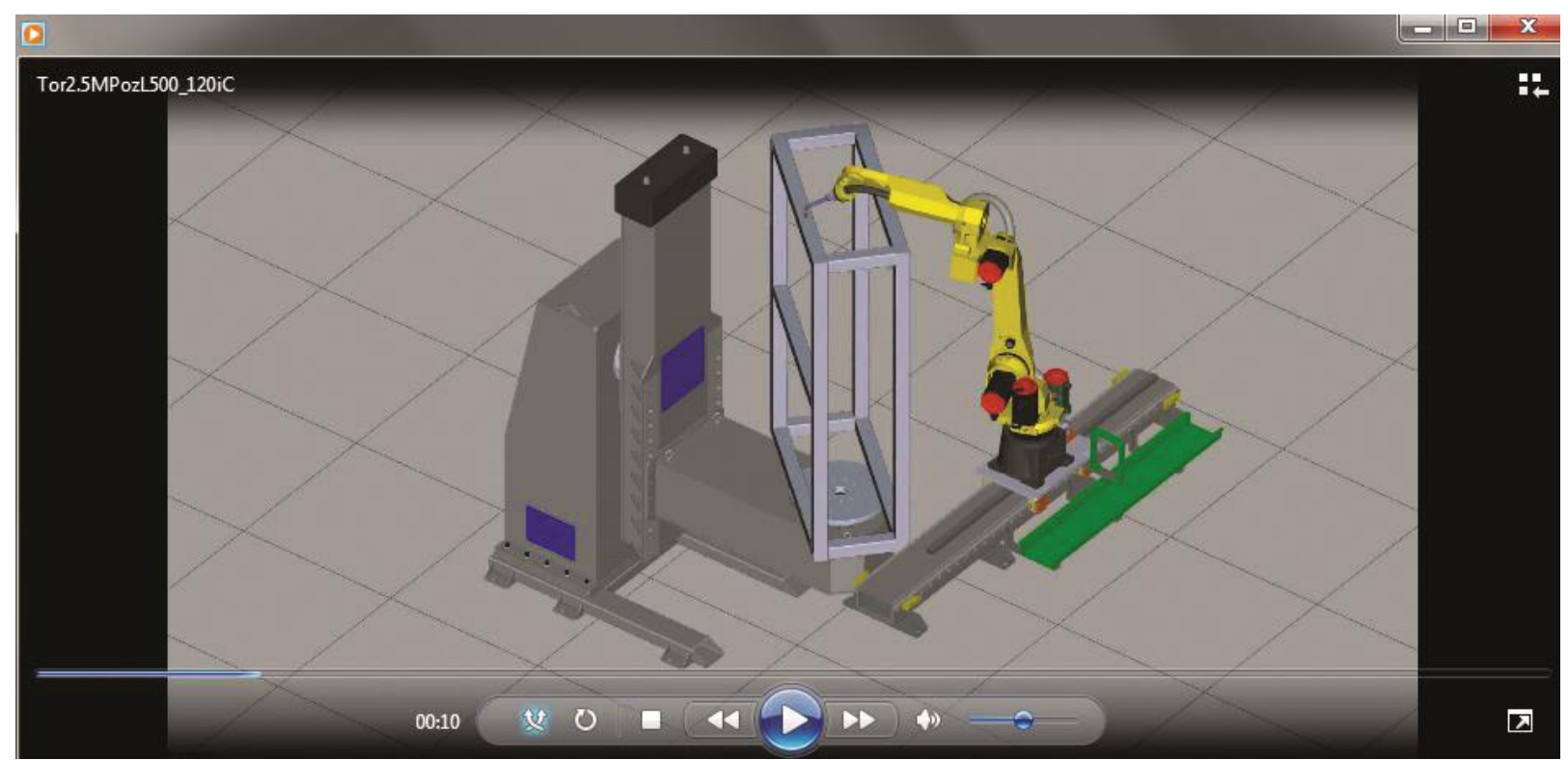

Fig. 10. Freeze-frame of the movie showing the synchronized work of a medium-sized robot and the tested "L" $500 \mathrm{~kg}$ positioner in a configuration with a $2.5 \mathrm{~m}$ floor moving track

\section{Strength tests}

The "L" biaxial positioner presented as an example was subjected to strength analysis using computer modeling tools based on the finite element method [5,11]. Examples of this type of modeling, which is certainly widely used in the design of engineering structures, can be found very rarely in scientific literature $[9,15]$. The design of the " $\mathrm{L}$ " positioner is quite complex and as shown in figure 3 it is made up from the $\mathrm{L}$ arm 
connected to the body on two legs. In addition, we can distinguish a rotary table, counterweights on the L arm, or drives that provide rotation of the arm and table disk. The positioner's calculation model had to be simplified in some places due to the inability to take into account the design of the drives, which are ready closed assemblies [4]. In their place, it is at most possible to introduce an additional load resulting from their total weight. In the first stage of calculations, the behavior of the $\mathrm{L}$ arm itself under a $300 \mathrm{~kg}$ load acting on the table disk was checked. The positioner's arm was connected to the non-deformable wall in the place where the arm's body is connected (Fig. 11a).

The preliminary model was used to assess stresses and deflections in the shoulder itself. The highest stresses occurred in the area of connection of the vertical arm and horizontal arm and amounted to $21.4 \mathrm{MPa}$, while the vertical deflection of the horizontal arm at its end reached a maximum of $-0.141 \mathrm{~mm}$ (Fig. 12). At such a low stress, there is no risk of permanent deformation for the assumed load. With an increase in load up to $500 \mathrm{~kg}$, the reduced stress increases to $29.1 \mathrm{MPa}$, and the vertical deflection of the end of the arm to DY $=-0.193 \mathrm{~mm}$.

At the next stage of analysis, there was already a full model of the positioner "L" (Fig. 11b) containing all elements, except for drives in the body and at the shield on the "L" arm. The results of calculations of stresses and displacements in the positioner loaded with a mass of $300 \mathrm{~kg}$ are shown in Figure 13.

Figure 13a shows the deformation of the model under a $300 \mathrm{~kg}$ load, which shows that the "L" arm itself retains its geometry, but only rotates under the influence of the bending moment acting relative to the horizontal axis of the drive of the body at the point of its connection with the "L" vertical arm. The largest vertical deflection of the end of the "L" arm was DY $=-1.65 \mathrm{~mm}$, and with a load of $500 \mathrm{~kg}$ DY $=-2.14 \mathrm{~mm}$.

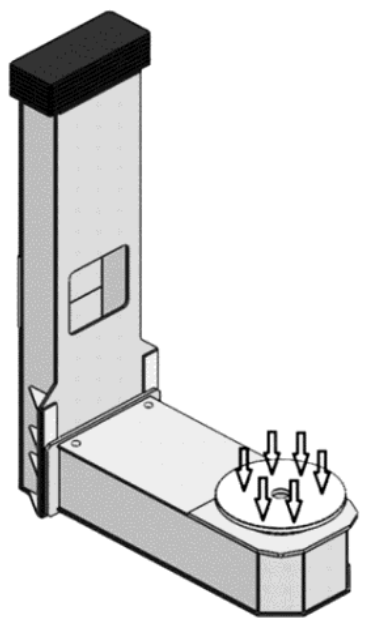

(a)

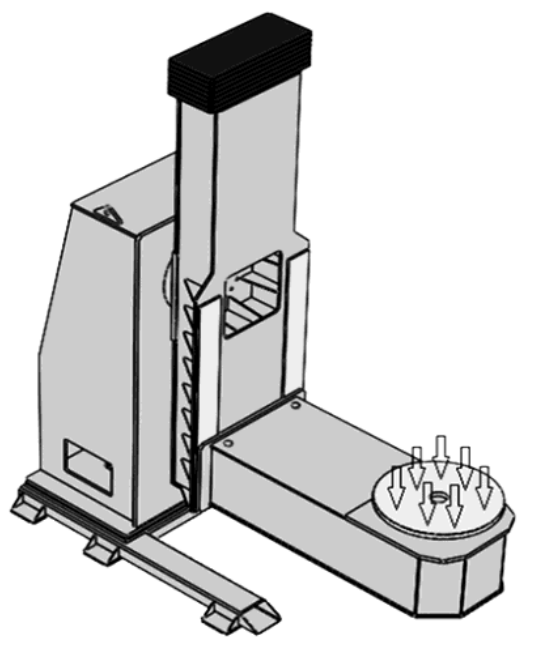

(b)

Fig. 11. L-type positioner models for strength analysis: a) initial model of the L arm itself, b) full L-type positioner model

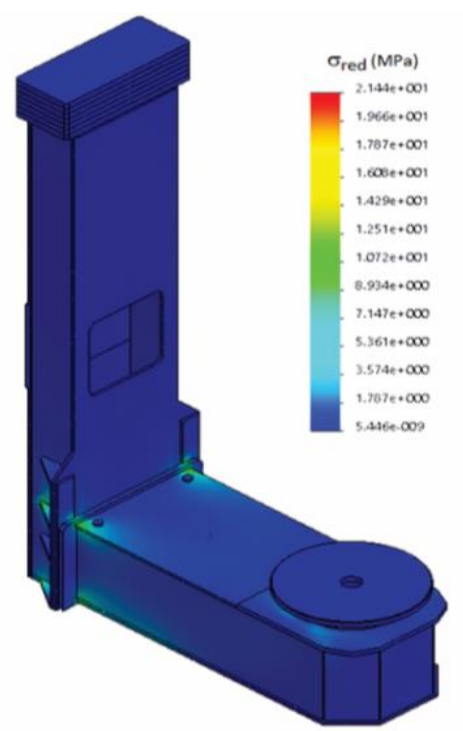

(a)

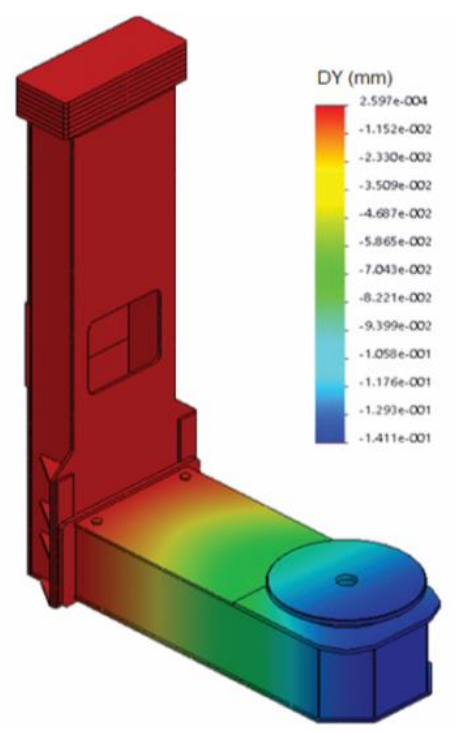

(b)

Fig. 12. a) Distribution of the reduced stresses $\sigma_{\mathrm{red}}$ and b) vertical displacements DY in the L-arm model under a load of $300 \mathrm{~kg}$ 


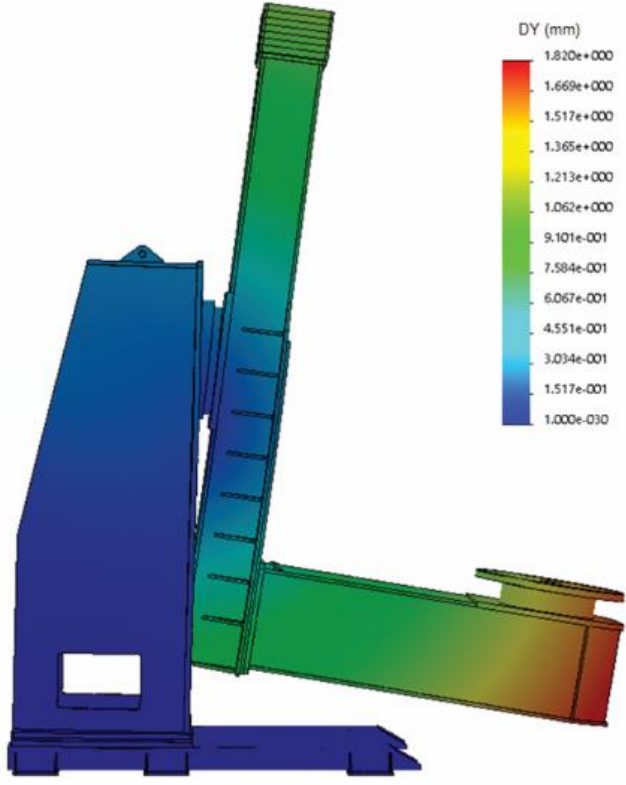

(a)

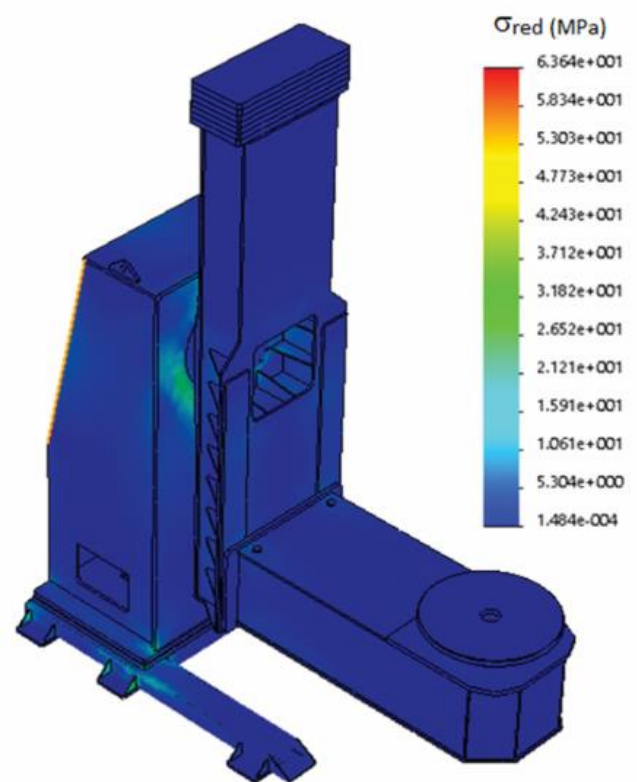

(b)

Fig. 13. a) Distribution of reduced stresses Gred and b) vertical displacement DY in a full L-type positioner model

The reduced stresses visible in figure 13b are concentrated in the places where the "L" arm is connected to the body and the base of the positioner body with the lugs. The areas of stress concentration in the positioner are shown in figure 14. The value of reduced stress reached the value of $63.1 \mathrm{MPa}$. When the load on the "L" arm disk increases to $500 \mathrm{~kg}$, the reduced stress increases to a maximum value of $76.6 \mathrm{MPa}$ (yield strength: $275 \mathrm{MPa})$.
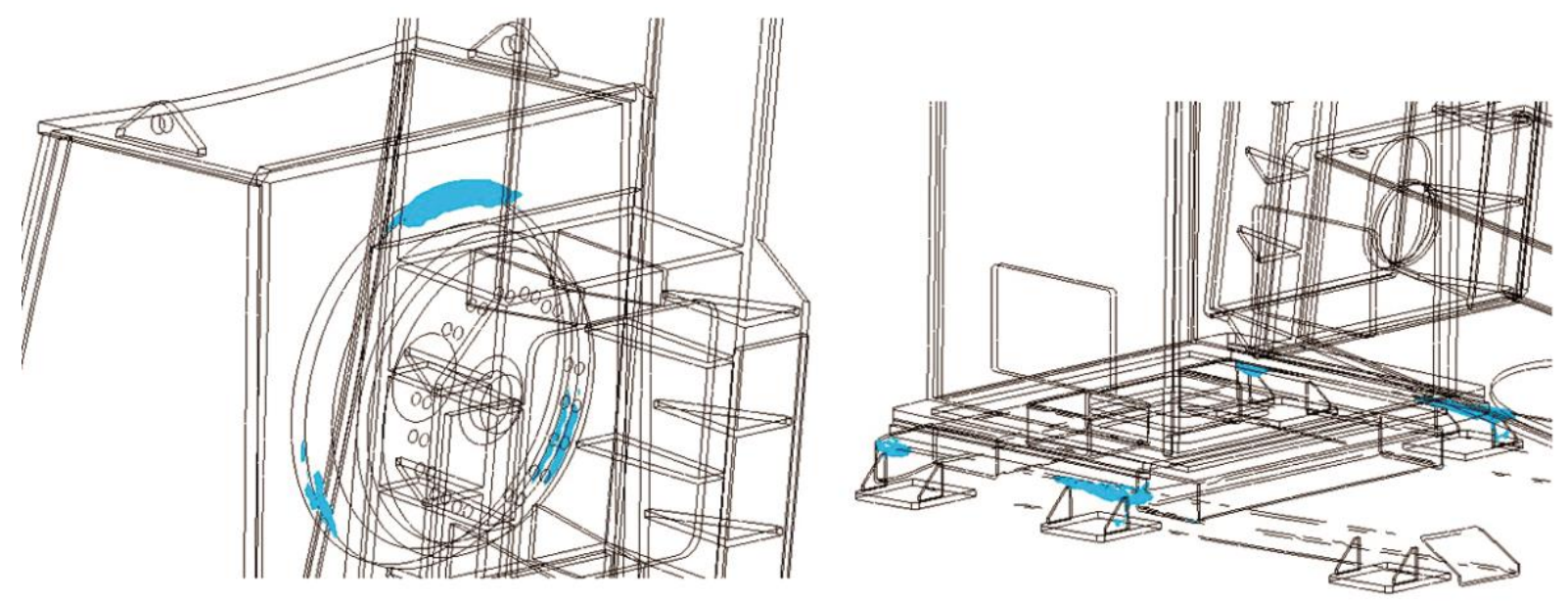

Fig. 14. Places of occurrence of stress concentration in the area of the connection of the arm $\mathrm{L}$ with the body and in the locations of the body on the feet

Subsequent strength analyzes of the "L" positioner included various variants of setting the "L" arm in the working space by rotating it relative to the initial position $\left(0^{\circ}\right)$ up to the inverted position (turning $45^{\circ}$, $90^{\circ}, 180^{\circ}$ ) (Fig. 15).

Collective modeling results for all variants of the "L" positioner are given in table I. Differences in stress values for the "L" positioner variants were small, while the increase in load translates into a gradual increase in stress and increased deflection at the end of the "L" arm. The most unfavorable variant occurs when the arm is tilted $45^{\circ}$ from the initial position. It should be noted that the deflection of the positioner disc between 0 and $180^{\circ}$ angles will lead to the creation of an additional torsional moment of "L" arm positioner.

Further possible actions aimed at improving the work of the positioner structure under load may involve the use of an additional counterweight on the vertical column of the $\mathrm{L}$ arm, raising the horizontal positioner beam to reduce the bending and torsion moment of the beam, e.g. changing or eliminating the technological hole in the vertical positioner column, or further structure modifications, such as changes in cross-sections of beams and shapes of structure elements. 


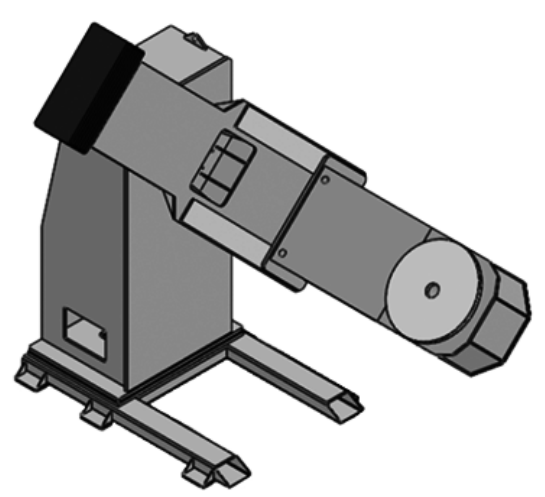

(a)

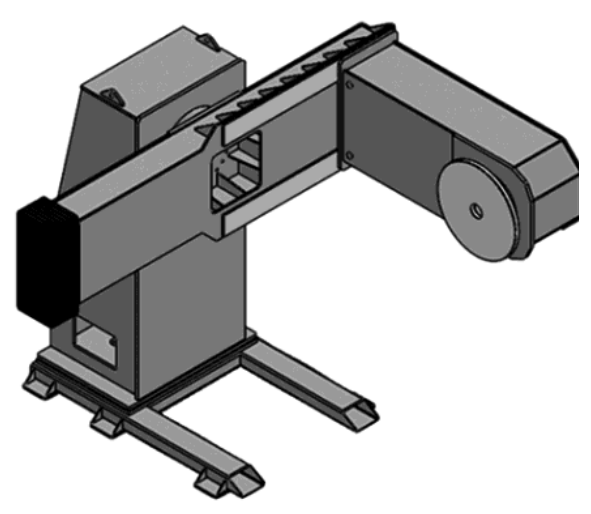

(b)

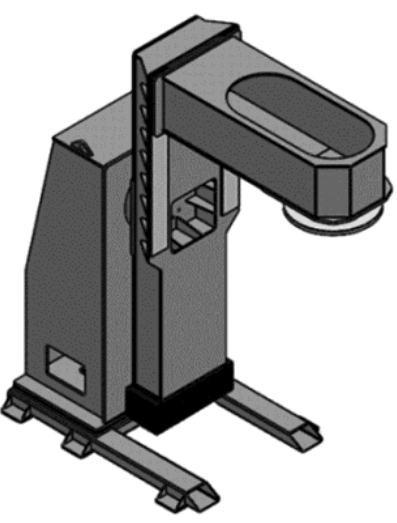

(c)

Fig. 15. Variants of $L$ arm position under load for strength analysis

Table I. A summary of the results of the calculation of the maximum values of stresses and displacements for the analyzed variants of $\mathrm{L}$ arm position and load on the positioner's rotating table

\begin{tabular}{cccc}
\hline $\begin{array}{c}\text { Arm position } \\
\mathbf{L}\left[{ }^{\circ}\right]\end{array}$ & $\begin{array}{c}\text { Load } \\
{[\mathbf{k g}]}\end{array}$ & $\begin{array}{c}\text { Reduced stress } \\
\boldsymbol{\sigma}_{\text {red }}[\mathbf{M P a}]\end{array}$ & $\begin{array}{c}\text { Vertical } \\
\text { displacement DY [mm] }\end{array}$ \\
\hline \multirow{3}{*}{0} & 300 & 63.6 & -1.65 \\
& 400 & 70.1 & -1.89 \\
& 500 & 76.6 & -2.14 \\
\hline \multirow{3}{*}{45} & 300 & 63.4 & -1.66 \\
& 400 & 71.7 & -1.90 \\
& 500 & 78.3 & -2.15 \\
\hline \multirow{3}{*}{90} & 300 & 63.4 & -1.64 \\
& 400 & 71.1 & -1.89 \\
& 500 & 77.7 & -2.13 \\
\hline \multirow{3}{*}{180} & 300 & 62.9 & -1.66 \\
& 400 & 70.8 & -1.90 \\
\hline
\end{tabular}

Based on the obtained modeling results for the initial model and the full model, fragments of the positioner structure were modified, which were aimed at improving its strength parameters and reducing deformation and deflection of structure elements. These changes were discussed earlier and included elongation of profiles in the base (in order to achieve better stability) and changes in dimensions due to the reinforced column of the main axis (the thickness of the sheet metal was changed: groove from 20 to $30 \mathrm{~mm}$ and side and top from 15 to $20 \mathrm{~mm}$, the size of the base plate changed slightly from $900 \times 650 \mathrm{~mm}$ to $900 \times 660 \mathrm{~mm}$, the bottom column plate has a constant thickness). In the vertical beam, in addition to the changes described earlier, its dimensions have been slightly modified from $2235 \times 700$ x $248 \mathrm{~mm}$ to $2249 \times$ $700 \times 250 \mathrm{~mm}$.

As a result of the introduced changes, a full modified "L" positioner model was developed, which was again subjected to strength analysis using finite element modeling. Figure 16 presents examples of the results of reduced stress distribution in the " $\mathrm{L}$ " positioner under a $300 \mathrm{~kg}$ load at two different positions of the " $\mathrm{L}$ " arm. The largest value of stress in the positioner for the $0^{\circ}$ position was $40 \mathrm{MPa}$, and for the $45^{\circ}$ position 50.7 $\mathrm{MPa}$ (Fig. 16b).

Improvements in deformation and deflection on the positioner's arm were also obtained. For example, the DY vertical displacement fell from -1.65 to -1.09 for a $0^{\circ}$ arm position at $300 \mathrm{~kg}$ load. However, when the arm is tilted by $45^{\circ}$, the maximum deflection was reduced from $-1.9 \mathrm{~mm}$ to $-1.6 \mathrm{~mm}$ at a load of $500 \mathrm{~kg}$. Similarly, for a $90^{\circ}$ tilt, the vertical deflection of the end of the arm dropped from -2.13 to $-1.8 \mathrm{~mm}$.

Figure 17 shows a comparison of the magnitude of maximum stress values and deflections in the horizontal beam of the "L" positioner for various variants of the analyzed calculation models. Further changes were introduced to the full model related to the increased counterweight on the vertical beam of the "L" arm, raising the horizontal arm position of the beam, as well as removing the technological hole in the vertical beam. The obtained calculation results show slight differences in stresses and deflections in the positioner. It was only the structural changes in the modified positioner that significantly improved its stiffness and further reduced the amount of stress reduced in the whole structure. 


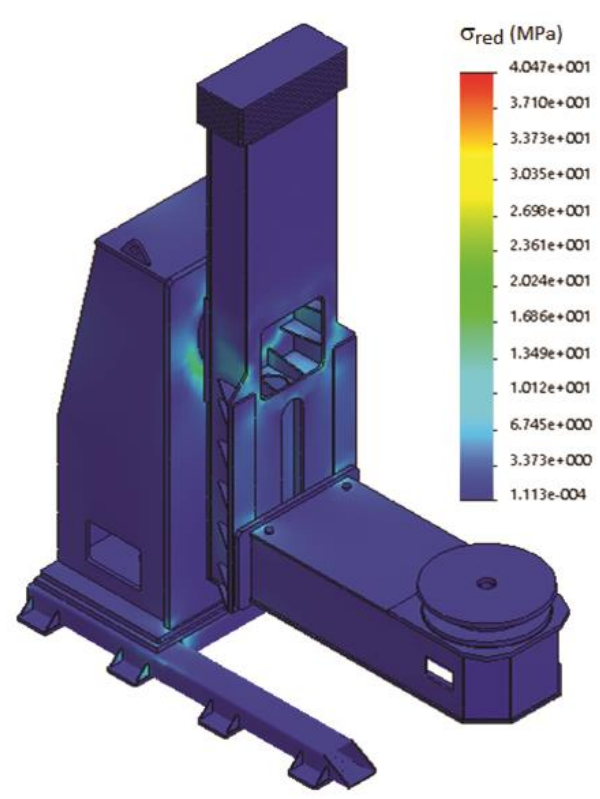

(a)

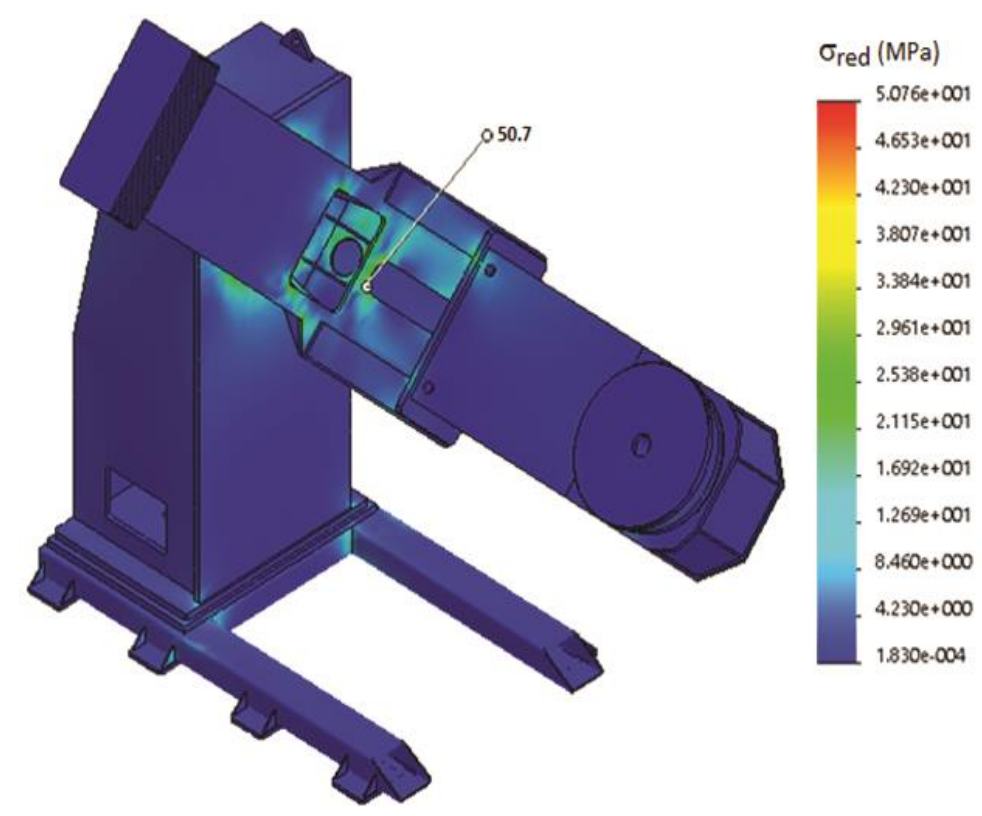

(b)

Fig. 16. Distribution of reduced stresses in a modified model of full positioner under $300 \mathrm{~kg}$ load at two L arm positions: a) $0^{\circ}$, b) $45^{\circ}$

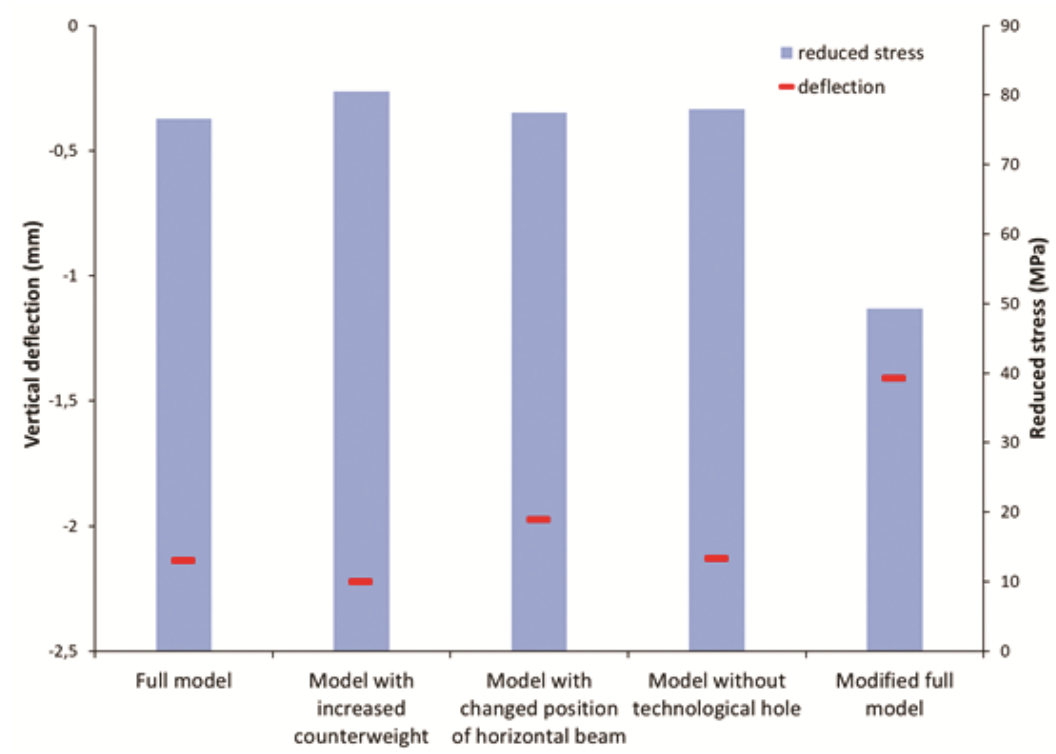

Fig. 17. Comparison of maximum values of reduced stresses and vertical deflections of the end of the positioner arm for different variants of the positioner's calculation models

\section{Summary}

Developing such a complex positioner, which is the "L" type structure, going from CAD modeling, through simulation and computational (strength) tests, to prototype construction and verification is a difficult task.

At the stage of design testing of new types of manipulators, in addition to standard analyzes of CAD construction documentation and FEM strength calculations, it is rational to conduct simulation motion tests in a virtual environment for off-line programming. This will eliminate the need to build real, expensive models, reduce the risk of research, speeding up the development and construction of prototypes.

The strength analysis carried out in "L" positioners showed the occurrence of small stress tensions in the whole structure and deflections at the end of the horizontal arm, whose value is the sum of deflections from the drives, the body, the place of connection of the drive and the body with the positioner's arm. Based on the results of calculations for the initial models of the "L" positioner, structural modifications were made in the area of connections of the body with the arm and the body with the positioner's base, resulting in a reduction of both stress and displacement values, which translate into the overall deformation of the structure. It is also possible to further reduce the total deflection of the positioner's arms by means of structural stiffeners of the body connection area with the positioner arm. The applied strength modeling 
of the "L" positioner is an indispensable tool at the stage of designing new manipulators, it allows to visualize potentially dangerous places in the structure and make modifications to stiffen it and counteract the unfavorable distribution of stress and bending moments.

Due to the special, unique nature of the developed prototype of the "L" positioner, his tests are not subject to dedicated standards and detailed literature descriptions (apart from general tests, e.g. checking the insulation resistance or electrical strength of low-voltage circuits). In the case of this type of devices, the verification is based primarily on the manufacturer's own procedures and recommendations formulated for key components, and also result from the specificity of a specific application of the tested machine, e.g. an attempt to determine the permissible welding current for a welding manipulator. The permissible linear and angular displacements (deflections and torsions) of structural elements can be analyzed both due to general strength requirements (and constitute a verification of calculation tests of structural models carried out by the finite element method), as well as with regard to the permissible loads of bearing supports or hubs of drive units. Not exceeding the recommended amounts will directly affect the safety and trouble-free operation of the device. The final stage of work on new positioner designs will be comprehensive prototype bench tests, and their results will be presented in subsequent publications.

Author Contributions: P.C. - conceptualization, methodology, analysis, writing; D.G. - methodology, investigation, analysis, writing; P.K., A.K., Y.K. - analysis, writing; T.S., B.S. - conceptualization, analysis, writing

Funding: The work was carried out as part of the project No. POIR.01.01.01-00-00-0271 / 16, 2014-2020 NCBiR

Conflicts of Interest: The authors declare no conflict of interest.

\section{References}

[1] Bolmsjo G.S., A kinematic description of a positioner and its application in arc welding robots. Automated and Robotic Welding, 1987, 11.

[2] Cegielski P., Golański D., Kołodziejczak P., Kolasa A., Sarnowski T., Studium rozwiązań konstrukcyjnych nowej generacji zewnętrznych osi robotów przemysłowych. Welding Technology Review, 2017, Vol. 89(11), 84-92.

[3] Cegielski P., Golański D., Kołodziejczak P., Kolasa A., Sarnowski T., Silbert B., Analiza ruchowa w układzie robot - zewnętrzne osie z wykorzystaniem wirtualnego środowiska do programowania robotów w trybie off-line, Welding Technology Review, 2018, Vol. 90(10), 13-22.

[4] Cegielski P., Kolasa A., Golański D., Kołodziejczak P., Rochalski D., Sarnowski T., Zaawansowane metody projektowania i weryfikacji torów jezdnych i pozycjonerów spawalniczych - zewnętrznych osi robotów, Biuletyn Instytutu Spawalnictwa w Gliwicach, 2018, Vol. 62(5), 35-41 [CrossRef]

[5] Cook R.D., Finite element modelling for stress analysis, John Wiley, 1995.

[6] Ghosh U.K., Design of Welded Steel Structures: Principles and Practice, CRC Press 2017.

[7] Hicks J., Welded design - theory and practice, Woodhead Publishing Limited, 2000.

[8] Honczarenko J., Roboty przemysłowe. Budowa i zastosowanie, WNT, Warszawa, 2011.

[9] İlman M.M., Karagülle H., Yavuz S., Integrated design and analysis of two axis gimbal welding positioner with 750 kg loading capacity, Conf. proceedings 18. National Machine Theory Symposium, Trabzon, Turkey, 5-7 July 2017.

[10] Kaczmarek W., Jużak I., Projekt zrobotyzowanego stanowiska do spawania kolan rur preizolowanych o różnej średnicy, Biuletyn WAT, 2012, Vol. LXI(1), 259-277.

[11] LUSAS Modeller User Manual v.14.0. FEA Ltd. UK.

[12] Malin V., Designer's guide to effectiwe welding automation - part I: analysis of welding operations as objects for automation, Welding Journal, 1985, 11.

[13] Pashkevich A.P., Dolgui B.A., Kinematic Control of A Robot-Positioner System for Arc Welding Application in: Industrial Robotics: Programming, Simulation and Application, ISBN 3-86611-286-6, pp. 702, ARS/plV, Germany, December 2006, Edited by: Low Kin Huat.

[14] Pierożek B., Lassociński J., Spawanie łukowe w osłonach gazowych, WNT, Warszawa 1987.

[15] Totala N.B, Bhutada S., Katruwar N., Rai R., Dhumke K., Design, Manufacturing and Testing of Circular Welding Positioner, International Journal of Engineering Research and Development, 2014, Vol. 10(2), 8-15.

[16] Zdanowicz R., Robotyzacja dyskretnych procesów produkcyjnych. Wydawnictwo Politechniki Śląskiej, Gliwice, 2009.

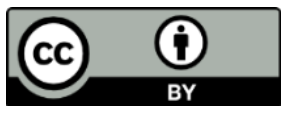

(C) 2019 by the authors. Submitted for possible open access publication under the terms and conditions of the Creative Commons Attribution (CC BY) license (http://creativecommons.org/licenses/by/4.0/). 